\title{
Antimicrobial Resistance Pattern in Escherichia coli Causing Urinary Tract Infection among Inpatients - A Retrospective Study
}

\author{
G. Sasikala, Usha Rani Ramavath* and Qader Ahmed Jalily
}

Department of Microbiology, Mahavir Institute of Medical Sciences, \#2-4-40, Shivareddypet, Vikarabad, Ranga Reddy - 501 101, Telangana, India

*Corresponding author

\section{A B S T R A C T}

\begin{tabular}{|l|}
\hline Ke y w o r d s \\
Antimicrobial \\
resistance, \\
$\begin{array}{l}\text { Escherichia coli, } \\
\text { MDR, therapy, UTI }\end{array}$ \\
\hline Article Info \\
\hline $\begin{array}{l}\text { Accepted: } \\
\text { 17 June } 2019 \\
\text { Available Online: } \\
\text { 10 July } 2019\end{array}$ \\
\hline
\end{tabular}

\section{Introduction}

Urinary tract infections (UTIs) are an important medical problem, being the second most common bacterial infection of humans after respiratory tract infection. They are often recurrent, difficult to treat, and can cause parenchymal damage to the kidney, leading to renal insufficiency and further complications (Draghijeva et al., 1999; Leroy et al., 2009
Urinary tract infections (UTIs) are second most common medical problem of humans after respiratory tract infection. They are often recurrent, difficult to treat, and can cause parenchymal damage to the kidney, leading to renal insufficiency and further complications. The aim is to study increasing rates of antimicrobial resistant Escherichia coli $(E$. coli) among patients admitted with urinary tract infections. The details of $E$. coli isolates from urine samples and their antibiotic sensitivity pattern were collected from the laboratory registers and the patient details were collected from the case records. The urine samples were processed using standard methods as per CLSI guidelines and antibiotic susceptibility was done by Kirby-Bauer disk diffusion test. Of the total 117 E. coli isolates, $27(23.8 \%)$ were isolated from in-patients, which were considered for the study. Of these 27 E. coli isolates, $15(55.55 \%)$ were multi drug resistant (MDR). The isolates showed high levels of resistance to ampicillin (81.48\%), amoxyclav (70.3\%), cefuroxime $(74.07 \%)$, cefazolin $(70.37 \%)$, cefotaxime $(62.96 \%)$, cefoxitin $(59.26 \%)$, Ciprofloxacin (74.07\%), norfloxacin (66.67).The isolates were highly sensitive to piperacillintazobactum (96.30\%), Meropenam (100\%), tobramycin (96.30\%), aztreonam (74.07\%), amikacin $(74.07 \%)$, nitrofurantoin $(74.07 \%)$ and, ceftazidime-clavulinic acid $(74.07 \%)$, co-trimoxazole $(74.07 \%)$ and tetracycline $(55.56 \%)$. Of the 15 cases of UTI are due to MDR E. coli, 14 improved on treatment and 1 was referred to higher centres. 
clonal group have made UTI management progressively more costly and challenging (Ikram et al., 2015; Johnson et al., 2012).

Escherichia coli are the leading cause of urinary tract infections in humans. Increasing rates of antimicrobial resistance among $E$. coli is a growing concern world-wide. However, to curb the problem, there is need of clinical data on the prevalence of resistance

Up to $60 \%$ of women have symptomatic UTIs during their lifespan, and $10 \%$ of men have UTIs annually. UTI in men is uncommon but often associated with structural abnormality (Nicolle et al., 2008). Since the resistance patterns of $E$. coli strains causing UTI varies considerably between regions and countries, a specific treatment recommendation may not be universally suitable for all regions or countries (Gupta et al., 2011). Active surveillance studies of in vitro susceptibility of uropathogens in women with uncomplicated cystitis are helpful in making decisions about empirical therapy (Gupta et al., 2011). Evidence proves that antibiotic-resistance genes were already present in the era before antibiotic therapy was available, and they probably originated from antibiotic-producing bacteria (Medeiros et al., 1997; Gardner et al., 1969). Indiscriminate use of antibiotics, inappropriate dosing, and incomplete treatment in both humans and also some animals are some of the factors leading to development of resistance in common bacteria (Sarkar et al., 2015).

Multidrug resistant (MDR) bacterial infections are now becoming quite common, not only in hospital settings but also in the community. Thus, this is not just a clinical problem now but a public health concern, especially in developing countries where the need for higher antibiotics puts a strain on the already restricted health budget. Escherichia coli (E. coli), a common human pathogen of the urinary tract, is well known for being MDR, including resistance to the fluoroquinolones. (Levy SB et al., 2004) This is especially common in South-East Asia. A very recent study from India showed high level (upto $80 \%$ ) of expression of drug efflux pumps in $E$. coli specimens, which is indicative of antimicrobial resistance (Sarkar et al., 2015). Similarly, another recent study from South India also depicted high levels of resistance to $\beta$-lactam and fluoroquinolones antibiotics in E. coli specimens isolated from urinary samples (Somashekara et al., 2014).

Since $E$. coli is the most common uropathogen in India, its drug resistance patterns will have the greatest impact on clinical management and the healthcare costs. (Hasan AS et al., 2007)

\section{Materials and Methods}

We carried out this study in a tertiary care hospital, Mahavir Institute of Medical sciences, Vikarabad, in south India. This was done in patients admitted from January to December 2018. Patients coming with symptoms of urinary tract infection (UTI with dysuria, hematuria, sudden incontinence, or increased frequency of urination were provisionally included. Out of 4167 urine samples $9.64 \%$ were obtained from inpatients over a period of one year (January to December 2018). Midstream urine (MSU) sample was collected in sterile, wide mouth, leak proof container and transported immediately to Microbiology laboratory. Cathetrized urine samples were collected as per standard guidelines. Semi-quantitative culture of urine was done on Cysteine Lactose Electrolyte Deficient (CLED) media, blood agar, and MacConkey agar by standard loop method. The culture plates were incubated at $37^{\circ} \mathrm{C}$ for $18-24 \mathrm{~h}$ under aerobic conditions. Identification of bacterial growth was confirmed by standard microbiological 
techniques (Forbes et al., 2007; Collee et al., 2008). Bacterial colony count more than $10^{5}$ colony-forming units (CFU)/ml was taken as significant bacteriuria.

Antibiotic sensitivity testing was done by Kirby-Bauer disc diffusion method on Mueller-Hinton agar, as per Clinical and Laboratory Standards Institute guidelines (Bauer et al., 1966; Clinical and Laboratory Standards Institute, 2017). Antibiotic discs were procured from HiMedia, Mumbai, India. ESBL screening and phenotypic confirmation was done by testing the strain against ceftazidime and ceftazidime/clavulanic acid, cefotaxime and cefotaxime/clavulanic acid. A difference of $>5 \mathrm{~mm}$ diameter of the zone of inhibition for combination disc in comparison to the ceftazidime/cefotaxime alone was considered as indicative of ESBL production. Escherichia coli ATCC 25922 for ESBL negative and Klebsiella pneumoniae 700603 for ESBL positive was used as reference strains. (Clinical and Laboratory Standards Institute 2017)

Discs of the following antimicrobial agents, were put up: ampicillin $(10 \mu \mathrm{g})$, amoxicillinclavulinic acid $(20 \mu \mathrm{g} / 10 \mu \mathrm{g})$, amikacin (30 $\mu \mathrm{g})$, cefazolin $(30 \mu \mathrm{g})$, cefoxitin $(30 \mu \mathrm{g})$ cefuroxime $(30 \mu \mathrm{g})$, cefotaxime $(30 \mu \mathrm{g})$, piperacillin-tazobactam $\quad(100 / 10 \mu \mathrm{g})$, ceftazidime-clavulanic acid $(30 / 10 \mu \mathrm{g})$, ciprofloxacin $(5 \mu \mathrm{g})$, norfloxacin $(10 \mu \mathrm{g})$, meropenem $\quad(10 \mu \mathrm{g}), \quad$ trimethoprimsulfamethoxazole $(1.25 \mu \mathrm{g} / 23.75 \mu \mathrm{g})$, aztreonam $(30 \mu \mathrm{g})$, tetracycline $(30 \mu \mathrm{g})$, Tobramycin $(10 \mu \mathrm{g})$ and nitrofurantoin $(300$ $\mu g)$.

The diameter of the zones of complete inhibition (as judged by unaided eye) was measured to the nearest whole millimeter using a scale, which was held on the back of the inverted petridish. Any presence of small colonies (>1 colony) or a light film of growth within the zone of inhibition indicated resistance of the isolate to that antimicrobial agent.

The zones of inhibition were measured and were interpreted as sensitive (S), intermediate sensitive (IS) or resistant (R) according to the disc manufacturer information tables. An isolate was considered as multidrug resistant (MDR) if it was resistant to at least three classes of antimicrobial agents viz. all penicillins and cephalosporins (including inhibitor combinations), fluoroquinolones, and aminoglycosides. Isolate was considered extensively drug resistant (XDR) if it was resistant to the three classes of antimicrobials described above (MDR) and also resistant to carbapenems (Manchanda et al., 2010)

The collected data was entered in Microsoft excel and then imported to SPSS. The collected data was analyzed using appropriate statistical methods.

\section{Results and Discussion}

In the present study 73 isolates $(18.15 \%)$ were obtained from 402 inpatient urine specimens. Table 1 shows the percentage distribution of IP samples in relation to age and sex. The females $(55.22 \%)$ had higher prevalence of UTI in comparison with males $(44.77 \%)$ Proximity of the female urethral meatus to anus, short urethra, and sexual intercourse have been stated as factors which influence the higher prevalence in women (Omoregie et al., 2008). The age group analysis showed that young female patients in the range of 21-40 years had highest prevalence rate of symptomatic UTI $(69.17 \%)$. Incidence of symptomatic UTI is high among patient with a history of recurrent UTIs, sexually active young women, and the risk is strongly associated with recent sexual intercourse, (Das RN et al., 2006). In present study males ( $\geq 60$ years) had a higher incidence of UTI $(56.6 \%)$ 
when compared with the elderly females (43.94\%) similar to study conducted by Sood et al., (2001) The rate of UTIs increases in men with advanced age, prostate enlargement and neurogenic bladder.

Total of $4167(\mathrm{IP}+\mathrm{OP})$ urine samples were received for culture and sensitivity during the study period. Among these, 717 samples (17.21\%) yielded significant bacteriuria; 2381 samples (57.1\%) showed no growth, 1026 (24.6\%) reported insignificant growth and 43 samples (1.03\%) showed mixed growth (Table 2).

In our study out of 402 urine samples from inpatients $\quad(n=73) \quad 18.15 \%$ were reported positive. The various organisms isolated from urine culture are shown in figure 1. Gram negative aerobic rods $(61.64 \%)$ dominated among which $E$. coli was the commonest uropathogen accounts for $37.5 \%$ followed by Klebsiella sp (16.6\%), MS-CNS (15.27\%), MRSA (8.33\%), MSSA \& MR-CNS accounts for $(6.9 \%)$, Proteus (4.16\%), Pseudomonas (2.7\%) Citrobacter sp. (1.3\%).

Out of 4167 samples, 117 (IP+OP) E. coli were isolated. 27 E. coli $(23.8 \%)$ were isolated from in-patients, which were considered for the study. Of these $27 E$. coli isolates, 15 (55.55\%) were multi drug resistant (MDR). The overall susceptibility patterns of E. coli isolates from various clinical sources is displayed in figure 2 . The isolates showed high levels of resistance to Ampicillin $(81.48 \%)$, amoxyclav $(70.3 \%)$ cefuroxime $(74.07 \%)$, cefazolin $(70.37 \%)$, cefotaxime $(62.96 \%)$, cefoxitin (59.26\%) Ciprofloxacin (74.07\%), norfloxacin (66.67). The isolates were sensitive to piperacillin-tazobactum (96.30\%), Meropenem (100\%), tobramycin (96.30\%), aztreonam (74.07\%), amikacin (74.07\%), nitrofurantoin (74.07\%) ceftazidime-clavulanic acid (70\%), cotrimoxazole $(74.07 \%)$, Tetracycline $(55.56 \%)$. Among 27 E. coli isolates, 17 (62.96\%) were ESBL producers (Fig. 3).

Of the 15 patients with UTI due to MDR $E$. coli, $14(93.33 \%)$ patients improved after the treatment, 1 case did not respond to the treatment and was referred to higher centres.

The most common risk factors associated with MDR E. coli were diabetes mellitus (7 patients, $46.66 \%$ ) followed by catheterisation (3, 20\%). The other risk factors were renal calculi $(2,13.33 \%)$ and renal pathologies (1 patients, 6.66\%). 2 patients did not have any of the risk factors. Studies from India have reported. E. coli as one of the commonest organisms causing UTI. In our study also $E$. coli was the commonest organism followed by Klebsiella species (Fig. 3 and Table 3).

Table.1

\begin{tabular}{|c|c|c|c|c|c|c|}
\hline \multirow[t]{3}{*}{ AGE } & \multicolumn{4}{|c|}{ GENDER } & \multicolumn{2}{|c|}{ TOTAL } \\
\hline & \multicolumn{2}{|c|}{ MALE } & \multicolumn{2}{|c|}{ FEMALE } & \multirow[t]{2}{*}{$\mathrm{M}+\mathrm{F}$} & \multirow[t]{2}{*}{$\%$} \\
\hline & $\mathrm{NO}$ & $\%$ & $\mathrm{NO}$ & $\%$ & & \\
\hline$<20$ Yrs & 49 & $55.68 \%$ & 39 & $44.32 \%$ & 88 & $21.89 \%$ \\
\hline 21-40 Yrs & 41 & $30.83 \%$ & 92 & $69.17 \%$ & 133 & $33.08 \%$ \\
\hline 41-60 Yrs & 53 & $46.09 \%$ & 62 & $53.91 \%$ & 115 & $28.61 \%$ \\
\hline \multirow[t]{2}{*}{$>60$ Yrs } & 37 & $56.06 \%$ & 29 & $43.94 \%$ & 66 & $16.42 \%$ \\
\hline & 180 & & 222 & & 402 & $100.00 \%$ \\
\hline
\end{tabular}

Table.2 


\begin{tabular}{|l|l|l|l|l|l|}
\hline CULTURE DATA & \multicolumn{2}{|l|}{ OUT PATIENT (OP) } & \multicolumn{2}{l|}{ IN PATIENT (IP) } & \\
\hline Urine Culture Data & Number & $\%$ & Number & $\%$ & Total \\
\hline No Of Samples & 3765 & 90.35 & 402 & 9.65 & 4167 \\
\hline No of Significant Bacteriuria & 644 & 17.01 & 73 & 18.3 & 717 \\
\hline No Of Insignificant & 970 & 26.29 & 56 & 13.9 & 1026 \\
\hline Culture Sterile/No Growth & 2120 & 56.3 & 261 & 64.9 & 2381 \\
\hline Mixed Growth & 31 & 0.87 & 12 & 2.99 & 43 \\
\hline
\end{tabular}

Table.3 Comparison with other studies

\begin{tabular}{|c|l|c|c|c|c|c|c|}
\hline $\begin{array}{l}\text { Study name, } \\
\text { year }\end{array}$ & $\begin{array}{l}\text { location } \\
\text { Indian } \\
\text { studies }\end{array}$ & Organisms & $\begin{array}{l}\beta- \\
\text { lactam }\end{array}$ & $\begin{array}{l}\text { Fluoro- } \\
\text { quinolon } \\
\text { es }\end{array}$ & $\begin{array}{l}\text { Nitro- } \\
\text { furantoin }\end{array}$ & $\begin{array}{l}\text { Amino- } \\
\text { glycosid } \\
\text { es }\end{array}$ & $\begin{array}{l}\text { Cotri } \\
\text { maxazole }\end{array}$ \\
\hline $\begin{array}{c}\text { Dash } \text { et al., } \\
(2013)\end{array}$ & East & E Coli & $58-94$ & $47-53$ & 10 & $6-16$ & 51.9 \\
\hline $\begin{array}{c}\text { Shakya } \text { et al., } \\
(2013)\end{array}$ & Central & E Coli & $29-41$ & $5-16$ & nd & nd & nd \\
\hline $\begin{array}{c}\text { Niranjanetal. } \\
\text { (2014) }\end{array}$ & South & E Coli & $22-88$ & 75 & 18 & 18 & 48.5 \\
\hline $\begin{array}{c}\text { Dugal } \text { et al., } \\
(2013)\end{array}$ & West & $\begin{array}{c}\text { gram negative } \\
\text { uro pathogens }\end{array}$ & $5-80$ & $70-80$ & 15 & $10-50$ & nd \\
\hline $\begin{array}{c}\text { Jayanthi ray } \\
\text { et al., (2015) }\end{array}$ & East & E Coli & $19-84$ & $19-62$ & 34 & $12-25$ & 31 \\
\hline Present study & south & E Coli & $59-81$ & $66-74$ & 26 & 26 & 25.93 \\
\hline
\end{tabular}

nd: not done

Fig.1 The various pathogens isolated were listed in

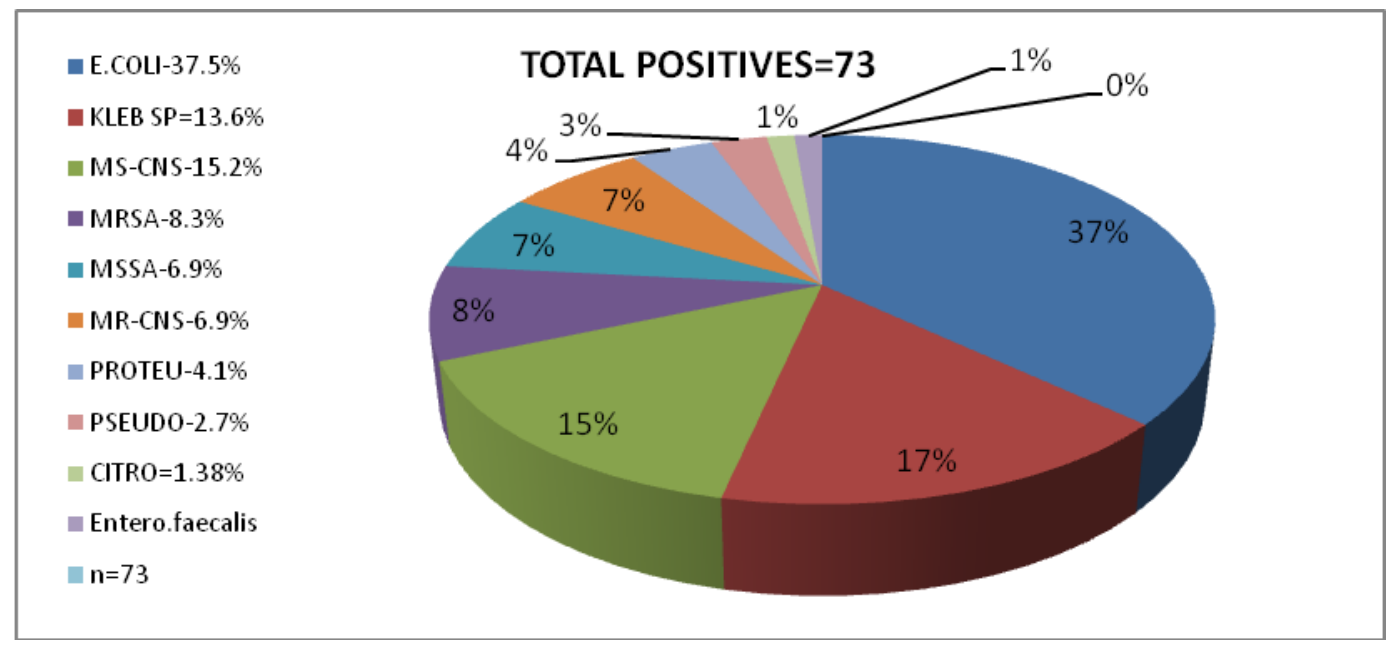

CPS = Coagulase Positive Staphylococci, CNS= Coagulase Negative Staphylococci, MSSA=Methicillin Sensitive Staphylococcus aureus, MRSA= Methicillin Resistant Staphylococcus aureus 
Fig.2 Antibiogram of $E$. coli isolates

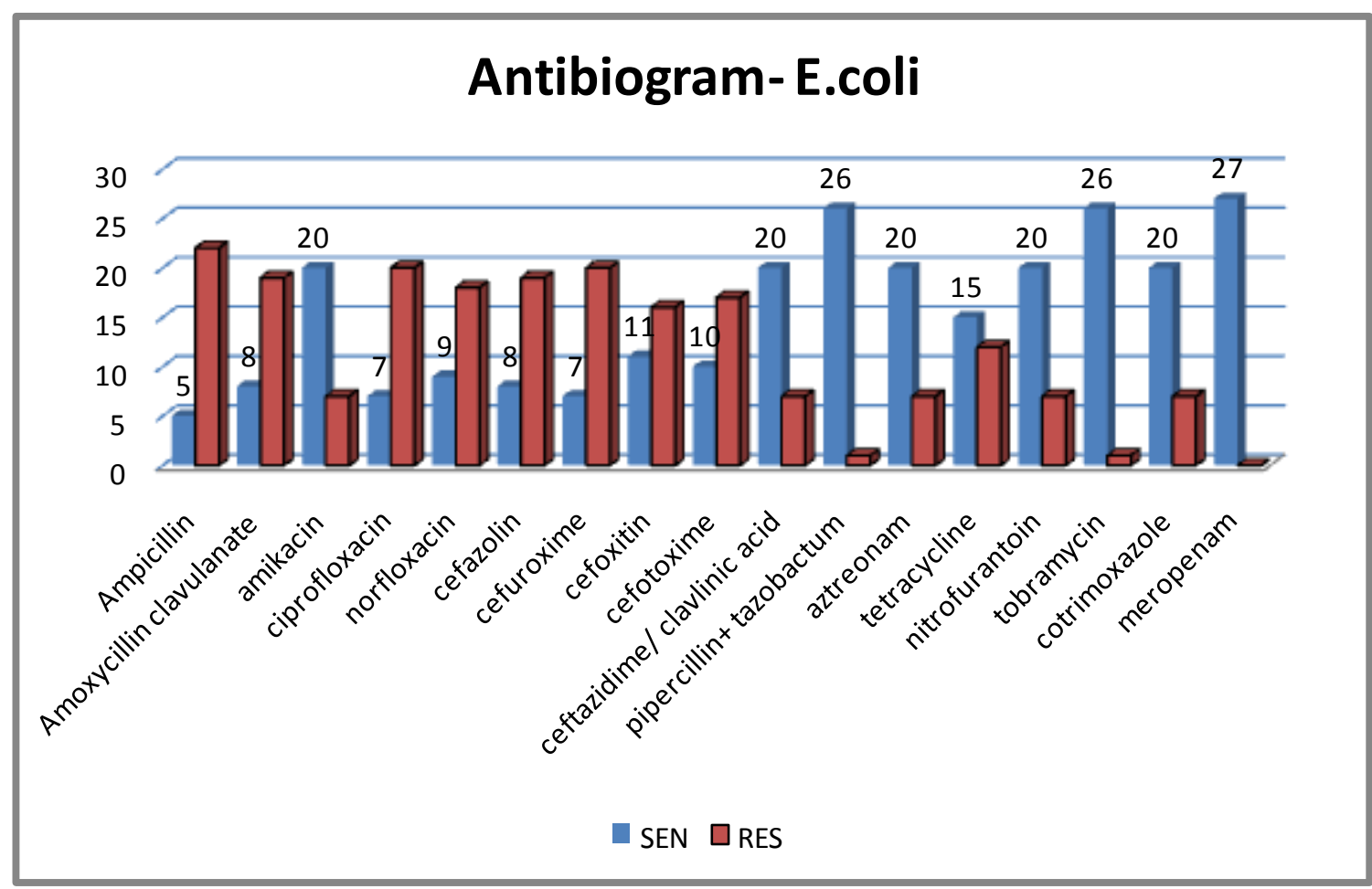

Fig.3 Showing ESBL producers

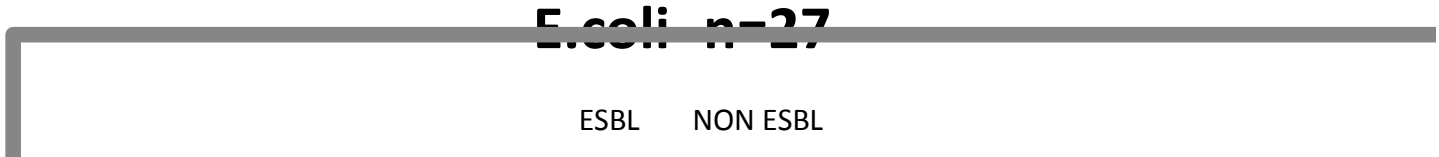

$37 \%$

$63 \%$

In our study, $55.55 \%$ isolates of $E$. coli were MDR. This is high when compared to other studies. Prevalence of MDR E. coli was about 52.9 per cent in a study done by Hasan et al., (2007) in a tertiary care Indian hospital and 7.1 per cent in a study done by Sahm et al., (2007) in USA. Study by Mathai et al.,
(2008) in southern India has showed that 8.4 per cent of commensal $E$. coli was MDR.

The antimicrobial sensitivity pattern of the $E$. coli isolates in our study was similar to previous studies done in India. The comparison of resistance patterns of 
uropathogenic $E$. coli in various studies is shown in Table 3. Dash et al., (2013), Shakya et al., (2013), Niranjan et al., (2014), Dugal et al., (2013), Jayanthi ray et al., (2015)

To conclude, this study showed high resistance among uropathogenic $E$. coli to ampicillin, fluoroquinolones and cephalosporins. The increased occurrence of UTI due to MDR E. coli could be due to increased prevalence of MDR strains in the community and due to common risk factor associated with MDR E. coli observed in our study

The limitations of the study were that it included only the inpatients, as a result of which the resistance rates could be high. The reason for this resistance is that ESBLs are encoded by plasmids, which also carry resistance genes for other antibiotics leading onto multidrug resistance. Multidrug resistance may be due to a number of factors like inappropriate self-medication, lack of prescribing regulations, substandard or falsified medicines and agricultural use of antibiotics.

ESBL producing $E$. coli has become the most causative agent in UTI. Other worrisome aspects of ESBL positive E. coli concern the high rate of resistance to non-beta lactam antibiotics, particularly quinolones and cotrimoxazole. The rising trend of ESBL production in E. coli is quite alarming as it limits the choices and outcome of antimicrobial treatment indicating the requirement of continuous monitoring systems and effective infection control measures.

This study concluded that multidrug resistant E. coli isolates are on rise and susceptibility to various antibiotics which is a matter of concern. Drug-resistance surveillance programmes should be run in hospitals to keep a check on antimicrobial resistance Policies should be implemented to curb over the counter sale of antibiotics and stringent measures should be undertaken to limit the spread of antibiotic resistance.

\section{References}

Bauer AW, Kirby WMM, Sherris JC, Turck M. Antibiotic susceptibility testing by a standardized single disc method. Am. J. Clin. Pathol. 1966; 45: 493-496.

Clinical and Laboratory Standards Institute. Performance Standards for Antimicrobial Susceptibility testing; CLSI document M100-S23.Wayne, PA: Clinical and Laboratory Standards Institute; 2017.

Collee JG, Miles RS, Watt B. Mackie \& McCartney's Practical Medical Microbiology 14th Ed. In: JG Collee, AG Fraser, BP Marmion, A Simmons, Editors. Churchill Livingstone: Indian Reprint; 2008

Das RN, Chandrashekhar TS, Joshi HS, Gurung M, Shrestha N, Shivananda PG. Frequency and susceptibility profile of pathogens causing urinary tract infections at a tertiary care hospital in western Nepal. Singapore Med J, 2006; 47: 281-5.

Dash M, Padhi S, Mohanty I, Panda P, Parida B. Antimicrobial resistance in pathogens causing urinary tract infections in a rural community of Odisha, India. J Family Community Med, 2013; 20: 20-6.

Draghijeva E. Virulence factors in Escherichia coli from children with pyelonephritis. Clinical Microbiology and Infection. 1999; 6: 328-333

Dugal S, Purohit H. Antimicrobial susceptibility profile and detection of extended spectrum beta lactamase production by Gram negative uropathogens. International Journal of 
Pharmacy and Pharmaceutical Sciences, 2013; 5 (4): 434-8.

Forbes BA, Sahm DF, Weissfield AS. Bailey and Scotts Diagnostic Microbiology. 12th ed. USA: Mosby Elsevier; 2007.

Foxman B, Barlow R, D’Arcy H, Gillespie B, Solbel J. Urinary tract infection: Selfreported incidence and associated costs. Annals of Epidemiology. 2000; 10: 509515

Gardner P, Smith DH, Beer H, Moellering $\mathrm{RC}$. Recovery of resistance $(\mathrm{R})$ factors from a drug-free community. Lancet 1969; 2: 774-6.

Griebling TL. Urologic diseases in America project: Trends in resource use for urinary tract infections in men. Journal of Urology. 2005; 173: 1288-1294

Gupta K, Hooton TM, Naber KG, et al., International clinical practice guidelines for the treatment of acute uncomplicated cystitis and pyelonephritis in women: a 2010 update by the Infectious Diseases Society of America and the European Society for Microbiology and Infectious Diseases. Clin Infect Dis 2011; 52: e103-e20.

Hasan AS, Nair D, Kaur J, Baweja G, Deb M, Aggarwal P. Resistance- patterns of urinary isolates in a tertiary Indian hospital. J Ayub Med Coll Abbottabad 2007; 19: 39-41.

Ikram R, Psutka R, Carter A, Priest P. An outbreak of multi-drug resistant Escherichia coli urinary tract infection in an elderly population: a case-control study of risk factors. BMC Infect Dis 2015; 15: 224.

James R. Johnson, Stephen B. Porter, George Zhanel, Michael A. Kuskowski, Erick Denamur. Virulence of Escherichia coli Clinical Isolates in a Murine Sepsis Model in Relation to Sequence Type ST131 Status, Fluoroquinolone Resistance, and Virulence Genotype. Infection and Immunity. 2012; 80:
$1554-1562$

Leroy S, Chalumeau $\mathrm{T}$, Ulinski $\mathrm{T}$, et al., Impressive renal damage after acute pyelonephritis in a child. Pediatric Nephrology. 2010; 25: 1365-1368

Levy SB, Marshall B. Antibacterial resistance worldwide: causes, challenges and responses. Nat Med 2004; 10 (Suppl 12): S122-9.

Manchanda V, Sanchaita S, Singh NP. Multidrug resistant Acinetobacter. J Global Infect Dis. 2010; 2 (3): 291-304.

Mathai E, Chandy S, Thomas K, Antoniswamy B, Joseph I, Mathai M, et al., Antimicrobial resistance surveillance among commensal Escherichia coli in rural and urban areas in Southern India. Trop Med Int Health 2008; 13: 41-5

Medeiros AA. Relapsing infection due to Enterobacter species: lessons of heterogeneity. Clin Infect Dis 1997; 2: 341-2.

Nicolle LE. Uncomplicated urinary tract infection in adults including uncomplicated pyelonephritis. UrolClin North Am 2008; 35: 1-12.

Niranjan V, Malini A. Antimicrobial resistance pattern in Escherichia coli causing urinary tract infection among inpatients. Indian J Med Res2014; 139: 945-8.

Omoregie R, Erebor JO, Ahonkhai I, Isobor $\mathrm{JO}$, Ogefere HO. Observed changes in the prevalence of uropathogens in Benin City, Nigeria. NZJ Med Lab Sci2008; 62: 29-31.

Prakash Kalra OM, Raizada A. Approach to a patient with urosepsis. Journal of Global Infectious Diseases. 2009; 1: 57-63

Ray J, Paul R, Haldar A, Mondol S. A study on antibiotic resistance pattern of Escherichia coli isolated from urine specimens in Eastern India. Int $\mathbf{J}$ Med Sci Public Health 2015; 4: 1670-1674

Sarkar SK, Bhattacharyya A, Mandal SM. 
YnfA, a SMR family efflux pump is abundant in Escherichia coli isolates from urinary infection. Indian $\mathrm{J}$ Med Microbiol 2015; 33: 139-42.

Shakya P, Barrett P, Diwan V, Marothi Y, Shah $\mathrm{H}$, Chhari $\mathrm{N}$, et al., Antibiotic resistance among Escherichia coli isolates from stool samples of children aged 3 to 14 years from Ujjain, India. BMC Infectious Diseases2013; 13: 477. Somashekara SC, Deepalaxmi S, Jagannath
Govindadas D. Retrospective analysis of antibiotic resistance pattern to urinary pathogens in a Tertiary Care Hospital in South India. J Basic Clin Pharm 2014; 5: 105-8.

Sood S, Gupta R. Antibiotic resistance pattern of community acquired uropathogens at a tertiary care hospital in jaipur, rajasthan. Community in south Trinidad. Saudi Med J 2001; 22: 53740.

\section{How to cite this article:}

Sasikala, G., Usha Rani Ramavath and Qader Ahmed Jalily. 2019. Antimicrobial Resistance Pattern in Escherichia coli Causing Urinary Tract Infection among Inpatients - A Retrospective Study. Int.J.Curr.Microbiol.App.Sci. 8(07): 2198-2206.

doi: https://doi.org/10.20546/ijcmas.2019.807.267 